\title{
Understanding primary and secondary sources of ambient carbonyl compounds in Beijing using the PMF model
}

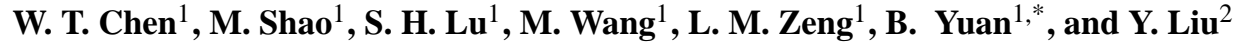 \\ ${ }^{1}$ State Joint Key Laboratory of Environmental Simulation and Pollution Control, College of Environmental Sciences and \\ Engineering, Peking University, Beijing, China \\ ${ }^{2}$ Chinese Research Academy of Environmental Sciences, Beijing, China \\ *now at: Earth System Research Laboratory, Chemical Sciences Division, NOAA, 325 Broadway, Boulder, Colorado 80305, \\ USA
}

Correspondence to: M. Shao (mshao@pku.edu.cn)

Received: 19 April 2013 - Published in Atmos. Chem. Phys. Discuss.: 13 June 2013

Revised: 11 February 2014 - Accepted: 15 February 2014 - Published: 26 March 2014

\begin{abstract}
Carbonyl compounds are important intermediates in atmospheric photochemistry. To explore the relative contributions of primary and secondary carbonyl sources, carbonyls and other volatile organic compounds (VOCs) were measured at an urban site in both winter and summer in Beijing. The positive matrix factorization (PMF) model was used for source apportionment of VOCs. As VOCs undergo photochemical processes in the atmosphere, and such processes may interfere with factor identification, the relationships between the contributions of the resolved PMF factors to each non-methane hydrocarbon (NMHC) species and its $k_{\mathrm{OH}}$ value were used to distinguish fresh factors and photochemically aged factors. As the result of PMF, five factors were resolved in winter, and two of them were identified as photochemically aged emissions. In summer, four factors were resolved, including one aged factor. Carbonyls abundances from aged factors were simulated by VOCs consumption and the corresponding carbonyl production yields, and the simulated abundances agreed well with the results obtained by the PMF model. The source apportionment results indicated that secondary formation was the major source of carbonyls in both winter and summer, with the respective contributions of $51.2 \%$ and $46.0 \%$. For the three major carbonyl species, primary anthropogenic sources contributed $28.9 \%$ and $32.3 \%$ to ambient formaldehyde, $53.7 \%$ and $41.6 \%$ to acetaldehyde, $68.1 \%$ and $56.2 \%$ to acetone in winter and summer, respectively.
\end{abstract}

\section{Introduction}

Carbonyls, including aldehydes and ketones, are a group of important oxygenated volatile organic compounds (OVOCs). As the key intermediates in the photo-oxidation of hydrocarbons, carbonyls are major sources of free radicals and are precursors of ozone, peroxyacyl nitrates and secondary organic aerosol (Singh et al., 1995; Finlayson-Pitts and Pitts, 1997; Liggio et al., 2005). Not only being produced from photo-oxidation of hydrocarbons, carbonyls also can be directly emitted into the atmosphere from a variety of natural and anthropogenic sources. The major anthropogenic emission sources of carbonyls include incomplete combustion of fuels, industrial processes, and solvent usage (Zhang and Smith, 1999; Ban-Weiss et al., 2008; Kim et al., 2008). Carbonyls can be lost from the atmosphere through reactions with the hydroxyl radical $(\mathrm{OH})$, photolysis, and deposition (Lary and Shallcross, 2000). Due to the complexity of carbonyl sources and sinks, it is a challenge to quantifying the relative contributions of primary emissions and secondary formation.

Previous studies have applied several techniques for the source apportionment of carbonyls. The multi-linear regression method is a commonly used technique, which separates primary and secondary carbonyls based on their correlations with markers for primary emission (e.g., CO, ethyne) and secondary production (e.g., $\mathrm{O}_{3}$, glyoxal) (Friedfeld et al., 2002; Garcia et al., 2006). However, this approach heavily depends on the selection of markers, and improper markers may bias source apportionment results. For primary 
emissions, some markers might be appropriate for certain emission sources (Rappenglück et al., 2010), and thus the use of a single marker for all primary emissions could be very risky (Friedfeld et al., 2002). In addition, reactive VOCs that are co-emitted with a primary emission marker can form secondary carbonyls during air mass transport. Hence, the correlation will also exist between secondary carbonyls and the primary marker. For secondary formation, the correlation coefficient and the slope between carbonyls and the secondary marker vary significantly depending on the $\mathrm{VOCs} / \mathrm{NO}_{\mathrm{x}}$ ratio and the degree of photochemical processing. Furthermore, primary carbonyls also can be precursors of these secondary markers, which may also lead to a correlation between them (Parrish et al., 2012).

To improve the multi-linear regression method, de Gouw et al. (2005) developed a parameterization method based on the degree of photochemical processing (i.e., photochemical age), with the consideration of the production of carbonyls by their precursors and the chemical removal of carbonyls during transport. This method made several assumptions which should be carefully considered: (1) anthropogenic emissions of carbonyls and their precursors are proportional to a primary marker. (2) The removal of VOCs is governed by the reactions with $\mathrm{OH}$ radicals. (3) Biogenic sources of carbonyls are proportional to the emission of isoprene. (4) The photochemical ages for sampled air masses can be determined (de Gouw et al., 2005). Positive matrix factorization (PMF), a receptor model, has also been used to separate sources of carbonyls (Bon et al., 2011; Buzcu Guven and Olaguer, 2011; Yuan et al., 2012; Zheng et al., 2013). Compared with the multi-linear regression method which employs one species for a certain source, the PMF model can use a number of species for source identification. Most previous studies identified several primary emission sources and a mixed secondary source among the PMF-resolved factors. However, Yuan et al. (2012) found that the PMF-resolved factors could be attributed to a common source at different stages of photochemical processing, rather than several independent sources. In addition to the various source apportionment approaches based on carbonyl measurements, Parrish et al. (2012) compared the primary emission flux of formaldehyde with fluxes of its precursors to quantify the relative contributions of primary and secondary formaldehyde sources. However, this approach relies on the accuracy of emission inventories and reaction mechanisms.

Large differences have been found among the abovementioned methods used to calculate sources of carbonyls. For example, several studies were conducted in the Houston area, TX, USA, to determine the contributions of primary anthropogenic sources of formaldehyde. Based on the multi-linear regression using $\mathrm{CO}$ as a primary marker, Friedfeld et al. (2002) reported that primary emissions contributed $36 \%$ of atmospheric formaldehyde. In a later study, Rappenglück et al. (2010) calculated the contributions of $38.5 \%$ and $8.9 \%$ for formaldehyde from primary vehicular emis- sions and industrial emissions, using $\mathrm{CO}$ and $\mathrm{SO}_{2}$ as primary markers, respectively. By using the PMF, Buzcu Guven and Olaguer (2011) estimated that mobile sources and industrial sources contributed $23 \%$ and $17 \%$ of formaldehyde, respectively. In contrast, by comparing emissions of formaldehyde and its precursors, Parrish et al. (2012) found that only $1 \%$ and $4 \%$ of formaldehyde were respectively emitted from vehicle exhaust and industrial sources, and that secondary formation accounted for the overwhelming majority of atmospheric formaldehyde. The source apportionment studies for carbonyls were also conducted in Beijing. Li et al. (2010) attributed $76 \%$ of atmospheric formaldehyde to direct anthropogenic emissions using the multi-linear regression method, while Yuan et al. (2012) calculated that this contribution was only $22 \%$ using the parameterization method. Compared with the number of formaldehyde studies, there were fewer source apportionment studies for other carbonyls, and most of these studies were conducted at different sites (Goldstein and Schade, 2000; de Gouw et al., 2005; Liu et al., 2009; Yuan et al., 2012; Guo et al., 2013). The only two studies that could be used for inter-comparison were taken in the summer in Beijing, and the apportioned primary contributions of acetaldehyde were $16 \%$ and $46 \%$ in 2005 and 2010, respectively (Liu et al., 2009; Yuan et al., 2012). It was unclear that such difference was caused by the variation of carbonyl sources or the uncertainty of source apportionment.

Though the State Council of China released mandatory requirement to improve air quality all over China, the way to achieve the goal could be very tough (Liu et al., 2013). Beijing is the capital of China and suffers from serious air pollution problems, characterized by high levels of ground-level ozone and $\mathrm{PM}_{2.5}$ (Shao et al., 2006; Wang et al., 2012a). Ambient carbonyls were detected at high levels in Beijing (Liu et al., 2009; Zhang et al., 2012) and formaldehyde displayed a significant positive trend from 1997 to 2010 (De Smedt et al., 2010). However, ambient concentrations of nonmethane hydrocarbon (NMHC) were found to decrease from 2003 (Wang et al., 2012b). It is essential to quantify contributions of different sources to carbonyls for understanding such trends and improving air quality in Beijing. Yuan et al. (2012) used the PMF model for carbonyl source apportionment in 2010 summer and found that factors in PMF were actually the results of different degrees of photochemical processing rather than individual sources. In this study, online measurements of carbonyls and other VOCs were conducted at Peking University (PKU) site in the winter and summer. We used PMF to apportion carbonyl sources in these two seasons with different degrees of photochemical processing. The degradation of NMHCs and production of carbonyls in the aged factors were analyzed based on the processes of photochemical aging to verify the PMF results. Differences in carbonyl sources between winter and summer were discussed and compared with previous studies. 


\section{Methods}

\subsection{VOCs measurements}

Online VOCs measurements were conducted at an urban site in Beijing from 4 August 2011 to 9 September 2011 and from 29 December 2011 to 18 January 2012. The sampling site was on the top of a six-floor building ( $\sim 20 \mathrm{~m}$ above ground) on Peking University campus. The PKU campus is located in the northwest of Beijing, about $500 \mathrm{~m}$ north of the Fourth Ring Road. This site was described in detail elsewhere (Song et al., 2008; Liu et al., 2009).

A custom-built online gas chromatography system equipped with a mass spectrometry and a flame ionization detector (GC-MS/FID) was used to measure C2-C10 hydrocarbons, C3-C6 carbonyls, C1-C4 alkyl nitrates, halocarbons, and methyl tert-butyl ether (MTBE), with a time resolution of $1 \mathrm{~h}$. CFC-113 (1,1,2-trichloro-1,2,2-trifluoroethane) was used as a natural internal standard from ambient air due to its long lifetime and minimal manmade emissions (W.T.. Liu et al., 2012). Daily calibrations were performed every day, and the variations of target species responses were required to be within $\pm 20 \%$ from the calibration curve. The detection limits for each species varied from 1 to $20 \mathrm{ppt}$, and the precisions ranged from $1 \%$ to $6 \%$. The detailed information of this system can be found in Yuan et al. (2012).

A commercial high-sensitivity proton-transfer-reaction mass spectrometry (PTR-MS) (Ionicon Analytik, Innsbruck, Austria) was used to measure 28 masses, including $\mathrm{C} 1-\mathrm{C} 4$ carbonyls and C6-C9 aromatics, with a time resolution of about $30 \mathrm{~s}$. Background signals were measured for $15 \mathrm{~min}$ every $2.5 \mathrm{~h}$ by diverting the ambient air sample flow through a Pt-coated quartz wool converter at $370^{\circ} \mathrm{C}$ (Yuan et al., 2013). Calibrations were done every two or three days, and the response factors varied within $20 \%$. The detection limits of each species varied from 40 to $200 \mathrm{ppt}$ except for formaldehyde. As the proton affinity of formaldehyde is only slightly higher than water, the back reaction of proton transfer becomes significant. The kinetic of PTR-MS formaldehyde detection was found to be mainly influenced by humidity (Vlasenko et al., 2010; Warneke et al., 2011). Therefore, we calibrated our formaldehyde measurement by using gas standards provided by a permeation tube (Kin-Tek, USA) at the humidity from $0-30 \mathrm{mmol} \mathrm{mol}^{-1}$ to obtain the curve of formaldehyde response factor on humidity. During the entire ambient measurement, formaldehyde signals were corrected according to the response curve. Due to the different ambient humidity between winter and summer, the detection limits of formaldehyde were $0.22-0.34 \mathrm{ppb}$ in winter and 0.45 $0.80 \mathrm{ppb}$ in summer at a time resolution of $30 \mathrm{~s}$. Among all our data, only less than $0.2 \%$ of formaldehyde concentrations in summer fell below the detection limit.

During these two campaigns, C3-C4 carbonyls, C6-C9 aromatics, isoprene and MVK+MACR (methyl vinyl ketone + methacrolein) were measured simultaneously by on- line GC-MS and PTR-MS. Good agreements were found between these two systems for most species, with correlation coefficients larger than 0.90 and slopes ranging from 0.8 to 1.2. Formaldehyde and acetaldehyde were only measured by PTR-MS. However, inter-comparison between the PTR-MS and 2,4-dinitrophenyl hydrazine-high-pressure liquid chromatography (DNPH-HPLC) methods (EPA TO-11A) was performed before the field measurements. By correcting the influence of humidity on formaldehyde response, a correlation coefficient of 0.93 and a slope of 1.06 were obtained between measurements by PTR-MS and DNPH-HPLC methods. The detailed results of inter-comparison were shown in the Supplement.

\subsection{Positive matrix factorization (PMF)}

The US Environmental Protection Agency's PMF 3.0 receptor model was used for VOCs source apportionment in this study. The PMF is a multivariate factor analysis tool which assumes that measured concentrations at receptor sites are linear combinations of contributions from different sources (Paatero and Tapper, 1994). Generally, an ambient data set can be viewed as a data matrix $\mathbf{x}$ with $i$ by $j$ dimensions, in which $i$ samples and $j$ chemical species are measured. The goal of multivariate receptor modeling is to identify the number $p$ of factors, the species profile $\mathbf{f}$ of each source, the mass g contributed by each factor to each individual sample, and the residual $\mathbf{e}$ (Eq. 1):

$\mathbf{x}_{i j}=\sum_{k=1}^{p} \mathbf{g}_{i k} \mathbf{f}_{k j}+\mathbf{e}_{i j}$.

The PMF solution minimizes the object function $Q$, based upon the uncertainties (Eq. 2):

$Q=\sum_{i=1}^{n} \sum_{j=1}^{m}\left[\frac{\mathbf{x}_{i j}-\sum_{k=1}^{p} \mathbf{g}_{i k} \mathbf{f}_{k j}}{\mathbf{u}_{i j}}\right]^{2}$,

where $\mathbf{u}$ represents the uncertainty of each data. The theoretical $Q$ ( $\left.Q_{\text {theoretical }}\right)$ can be calculated as Eq. (3), and the best PMF solution should have $Q / Q_{\text {theoretical with the value }}$ of $\sim 1$.

$Q_{\text {theoretical }}=i \times j-p \times(i+j)$

The basic assumption of the PMF model is that the fitting species are not allowed for chemical losses or production. Thus, apportioning carbonyl sources using the PMF model should be approached with care. As mentioned in the introduction, several studies apportioned carbonyl sources by using the PMF model (Bon et al., 2011; Buzcu Guven and Olaguer, 2011; Zheng et al., 2013). However, the study to investigate the validity of the results was not available yet. Yuan et al. (2012) proved the capacity of the PMF approach in identifying the role of chemical aging for better understanding the PMF factors. The VOC emission ratios derived from the PMF fresh factors agreed well with the ones calculated based on photochemical ages, indicating that the PMF 
Table 1. The sum of formaldehyde and acetaldehyde concentrations in Beijing (unit: ppb).

\begin{tabular}{rrc}
\hline Year & Summer & Winter \\
\hline 2005 & $21.7^{\mathrm{a}}$ & $7.0^{\mathrm{a}}$ \\
2006 & $13.12^{\mathrm{b}}$ & \\
2008 & $13.3^{\mathrm{c}, \mathrm{d}}$ & $6.6^{\mathrm{e}}$ \\
2009 & $11.4^{\mathrm{e}}$ & $5.9^{\mathrm{e}}$ \\
2010 & $12.6^{\mathrm{e}}$ & \\
2011 & $8.0^{\mathrm{f}}$ & $8.1^{\mathrm{f}}$ \\
\hline
\end{tabular}

a(Pang and $\mathrm{Mu}, 2006)$,

b(Shao et al., 2009),

c(Xu et al., 2010),

$\mathrm{d}_{\text {data before traffic restriction in } 2008 \text {, }}$

$\mathrm{e}$ (Zhang et al., 2012)

f this study.

approach could identify the contributions from primary emissions reasonably. Additionally, the abundances of NMHCs in the PMF-aged factors could be reproduced by the photochemical aging of fresh factors. In this study, we run PMF models using two VOC data sets from different seasons, and discussed the apportionment results to investigate whether the PMF approach can separate carbonyl sources well.

For the PMF analysis, uncertainties of online GC-MS/FID and PTR-MS measurements were calculated using the method by Yuan et al. (2012). Generally, for the species measured by the GC-MS/FID system, the uncertainties were calculated as the sum of $10 \%$ of measured concentrations and one-third of detection limits. For the species measured by the PTR-MS, the uncertainties were calculated as the sum of $10 \%$ of concentrations and the errors from mass spectrometer measurements. Finally, only species with high signal-tonoise ratios and few missing data values were used for the PMF analysis. In winter, 10 carbonyls, 26 NMHCs, 2-butyl nitrate $\left(2-\mathrm{BuONO}_{2}\right)$, tetrachloroethylene, and MTBE were used. In summer, most of the values of cis/trans-2-butene and cis/trans-2-pentene fell below the detection limits, so these 4 species were not used for the PMF analysis.

In this work, the PMF factor numbers were explored from 3 to 8 for the best solution. The final numbers of factors depended on two aspects: (1) $Q / Q_{\text {theoretical }}$, which was used to characterize the quality of the reconstruction, and (2) the physical plausibility of the factors (Bon et al., 2011). Fourand five-factor resolutions were selected in summer and winter, respectively. The free rotation of the PMF factors was investigated by adjusting the Fpeak parameter between -5 and 5. The results with non-zero Fpeak values were generally consistent with the runs with zero Fpeak values, and thus the results used in this study were from the runs with non-rotation.

As the PMF-resolved factors might be influenced by photochemical processes, we used the relationship between the contribution of one factor to each NMHC species and its chemical reactivity $\left(k_{\mathrm{OH}}\right)$ to distinguish fresh and aged fac- tors, as performed by Yuan et al. (2012). Generally, if all PMF-resolved factors were originated from fresh emissions, the distribution of each species would not correlate with its chemical reactivity. As the air mass from a source was ageing, the NMHCs underwent photochemical reactions, and the more reactive species would be more largely consumed. As a result, a negative correlation could be seen between an aged factor contribution to each NMHC species and its $k_{\mathrm{OH}}$ value. Considering that such complex relationships were difficult to express in mathematical formulae, Spearman's coefficient of rank correlation $\left(r_{\mathrm{s}}\right)$ was used to represent the relationship.

\section{Results and discussion}

\subsection{Characteristics of ambient carbonyls in Beijing}

The average concentration of the 10 measured carbonyls in Beijing was $13.2 \pm 7.9 \mathrm{ppb}$ (average value \pm standard deviation) in winter. In summer, the average concentration went up to $16.3 \pm 7.4 \mathrm{ppb}$. Formaldehyde, acetone, and acetaldehyde were the three major species, contributing more than $80 \%$ of the total measured carbonyls in both seasons. Ambient concentrations of carbonyls in Beijing were measured by several previous studies from 2005 (Pang and Mu, 2006; Shao et al., 2009; Xu et al., 2010; Zhang et al., 2012). During the recent years, VOC sources changed remarkably in Beijing, resulting from quick increment of vehicular population, stricter standards for vehicle emissions (Zhang et al., 2012) and solvent compositions (Yuan et al., 2010), and dramatic changes in industries. Table 1 shows the sum of measured formaldehyde and acetaldehyde concentrations in Beijing during 2005-2011. The measured concentrations in summer showed a significant decrement from 2005 to 2006 and from 2010 to 2011, while the wintertime concentrations did not exhibit a significant change. Some of the above studies provided daily average concentrations of formaldehyde and acetaldehyde, but some measurements were conducted only in daytime. To check the effect of diurnal variations, we compared the daytime average concentration (from 08:00 to 20:00 LT) and daily average concentration of these two carbonyls in 2011. The result showed that the relative differences between the daytime and daily average concentrations were very low, with the values of $7 \%$ in summer and $1 \%$ in winter. It seemed the daytime and daily average concentrations of these carbonyls provided by previous studies can be compared to investigate carbonyl trends. In contrast with the decreasing trend of carbonyl levels derived from ground-based measurements, satellite measurements suggested that formaldehyde columns showed an increasing trend (De Smedt et al., 2010). As the satellites measurements were conducted in midday and covered a larger spatial scale, the ground-based measurements were considered to better represent the trend of $24 \mathrm{~h}$ carbonyl concentrations in the urban area of Beijing. The decreasing trend for 

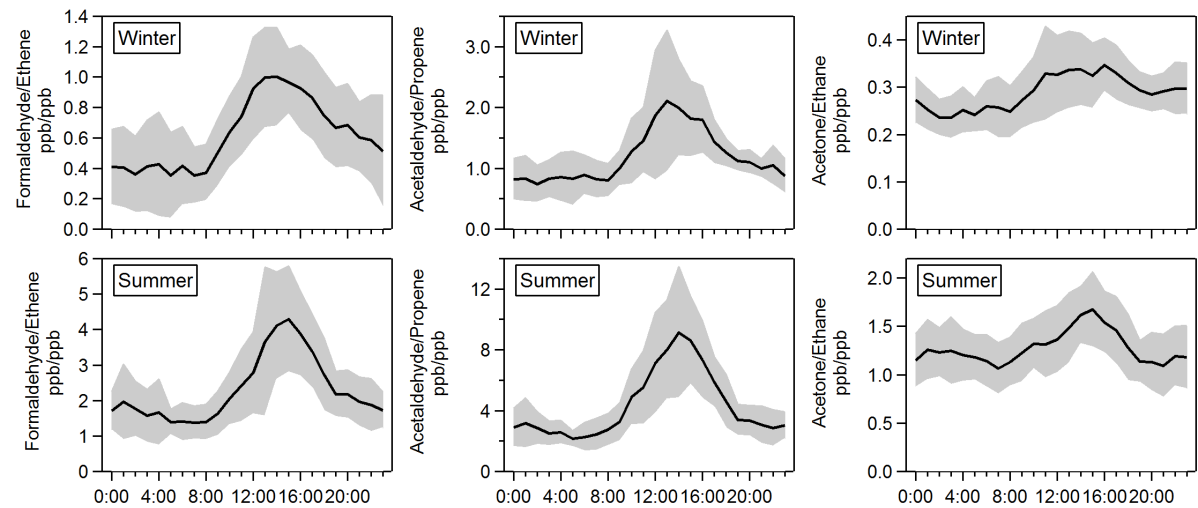

Fig. 1. Diurnal variations of measured ratios of formaldehyde/ethene, acetaldehyde/propene, and acetone/ethane at the PKU site during winter and summer. Black lines represent the average values and grey shaded areas indicate standard deviations.

summed concentrations of formaldehyde and acetaldehyde indicated that the emission controls on these carbonyls or their precursors in Beijing possibly made progress during the past years. However, the flat trend during winter suggested that there might be some important sources for carbonyls in winter were not under effective control.

Figure 1 shows the diurnal variations of ratios of formaldehyde / ethene, acetaldehyde / propene, and acetone / ethane at the PKU site during winter and summer. Ambient concentrations of carbonyls were influenced by meteorological conditions and the emission strengths of carbonyls and their precursors. Assuming that the direct emissions of carbonyls from anthropogenic sources were proportional to the emissions of NMHCs, the diurnal variations of carbonyl / NMHC ratios could reflect the importance of secondary formation to ambient carbonyls. These three pairs of carbonyls and NMHCs were chosen because the two species in each pair had similar reaction rates with $\mathrm{OH}$ radicals (Atkinson et al., 2006). As a result, the two species in the atmosphere were removed approximately equally by reactions with $\mathrm{OH}$ radicals, and therefore the effect of photochemical degradation on their ratios can be neglected. As shown in Fig. 1, the measured carbonyl / NMHC ratios showed similar daily variations both in summer and winter: they were stable during nighttime, increased after sunrise (about 08:00 LT), and reached a maximum in the early afternoon (about 13:0015:00 LT), then decreased to low values at night. This variation indicated an important contribution from secondary production during the daytime both in winter and summer. The diurnal variations of the acetone / ethane ratios were less than those for formaldehyde / ethene and acetaldehyde/propene. Such difference was consistent with previous studies, which found that secondary production of acetone was less important than that of formaldehyde and acetaldehyde (de Gouw et al., 2005; Yuan et al., 2012).

Though the diurnal patterns of carbonyl/NMHC ratios were similar in winter and summer, the values of carbonyl / NMHC ratios were approximately 3-5 times higher in summer than those in winter, during both day and night. As mentioned above, ambient concentrations of carbonyls did not show significant discrepancies between these two seasons. The seasonal differences of carbonyl/NMHC ratios were mainly due to the much higher NMHC levels in winter. This also indicated the significant differences in VOC sources between these two seasons. Considering the effects of photochemical processing on VOC ratios were minor at night, nighttime VOC ratios were close to their emission ratios (Wang et al., 2013). Therefore, the higher nighttime carbonyl / NMHC ratios in summer indicated that the fraction of NMHCs in primary emitted VOCs was higher in winter than that in summer, whereas carbonyls fraction was higher in summer.

Previous studies usually supposed that carbonyls in winter mainly came from direct anthropogenic emissions (Pang and $\mathrm{Mu}$, 2006; Cerón et al., 2007). From our measurements, the differences of carbonyl/NMHC ratios between noon and night in summer were only slightly larger than the differences in winter. The noon/night ratios were 2.6 and 3.1 for formaldehyde/ ethene, 2.6 and 3.5 for acetaldehyde / propene, and 1.4 and 1.5 for acetone / ethane in winter and summer, respectively. This indicated that secondary formation was still an important source of carbonyls in winter. It should be noted that photolysis removal of carbonyls was also considered here besides the removal by reactions with $\mathrm{OH}$ radicals. According to our estimation, reaction with $\mathrm{OH}$ was the main pathway of carbonyl removal. The photolysis contributed $33 \%, 1 \%$ and $12 \%$ to the losses of formaldehyde, acetaldehyde and acetone at daytime, and these contributions showed no significant difference between winter and summer. The details for the calculation of carbonyl removal rates were shown in the Supplement. As a result, neglecting the photolysis of carbonyls had little effect on comparing the contributions of secondary formation between winter and summer, and the variation of carbonyl / NMHC ratios could reflect the importance of secondary formation. For further discussion, the PMF model was used for carbonyls source 

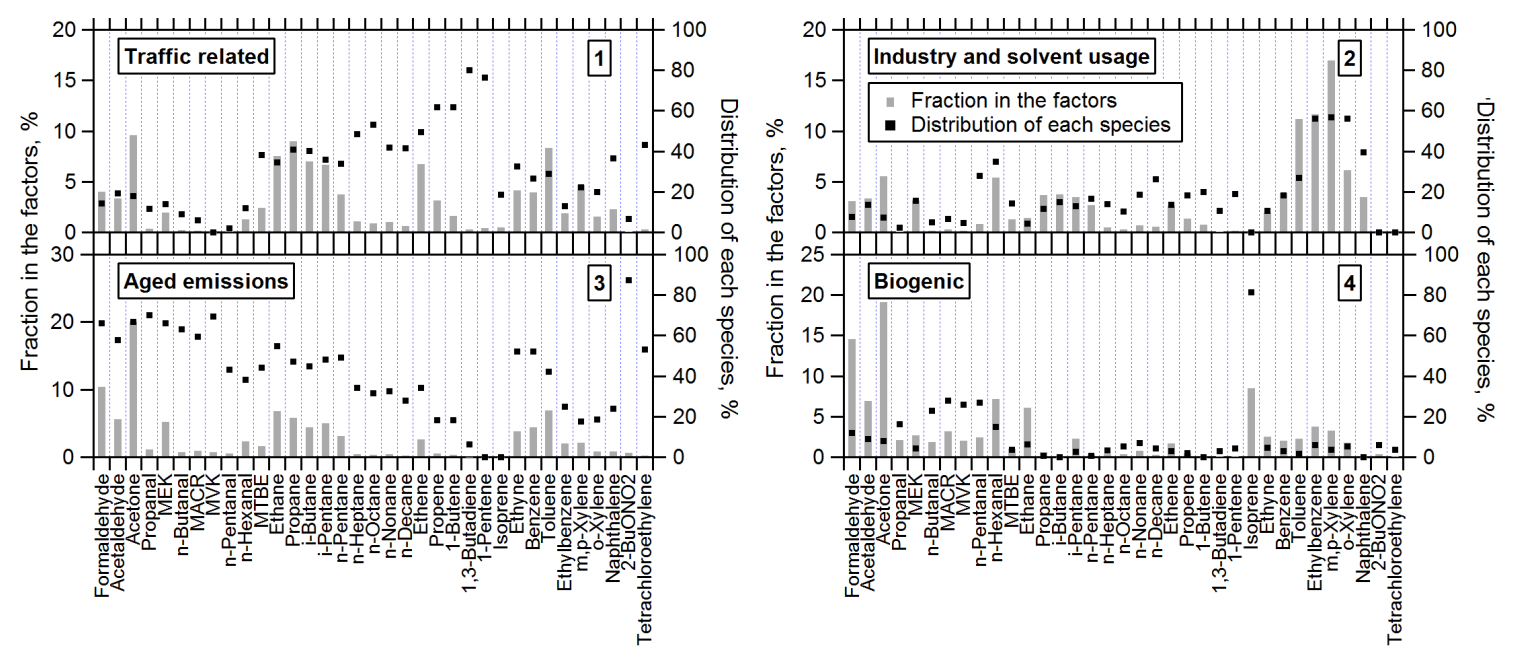

Fig. 2. Profiles of the four factors resolved by the PMF model and the distributions of species among these factors in summer.

apportionment to determine relative contributions from primary and secondary sources.

\subsection{Identifying PMF factors}

The PMF model is a mathematical tool which separates pollutants according to the correlations among species, and the understanding of PMF factors is subjective to a certain extent. We were aware of the deficiency of the PMF model when apportioning VOC sources. In this section, we compared the profiles derived by the PMF model with previously measured ones to check the reliability of resolved fresh factors. In the next section, we tried to identify aged factors by investigating the relationship between degradation of primary emitted VOCs and production of carbonyls.

For summertime measurements, 593 samples were used for the PMF analysis, and four factors were identified. The profiles of resolved PMF factors and the distributions of species among the factors were shown in Fig. 2. The profiles were expressed as the mass percentage of individual VOC species in each factor, and the distributions represented the contributions of individual factors to the measured level of each species.

Factor 1 made an important contribution to our measured alkanes and alkenes. The profile of this factor was dominated by $\mathrm{C} 2-\mathrm{C} 5$ alkanes, $\mathrm{C} 2-\mathrm{C} 3$ alkenes, ethyne, and aromatics. These species were mainly emitted from exhaust of vehicles and evaporation of gasoline (Liu et al., 2008). This factor explained $38.1 \%$ of the measured MTBE, which was commonly used as a tracer of gasoline vehicle emissions (Chang et al., 2006). Previous studies also reported that traffic-related emissions were the most important NMHCs sources in summer of Beijing (Song et al., 2008; Wang et al., 2010). We therefore attributed this factor to traffic-related emissions.

In factor 2, the loadings of aromatics, including benzene, toluene, ethylbenzene and xylenes, were high. Aromatics were reported to be major constituents of solvents (Yuan et al., 2010), which were widely used in industrial processes as well as some household products. Thus, we considered this factor to be related to industry and solvent usage.

Factor 3 had contributions to almost all measured VOC species, except for some very reactive species. This factor accounted for more than $60 \%$ of our measured carbonyls and $87.5 \%$ of our measured $2-\mathrm{BuONO}_{2}$ levels. Alkyl nitrates were believed to be mainly from secondary production in urban regions and had relatively long lifetimes (Simpson et al., 2003). Thus, we identified this factor as aged emissions.

Factor 4 contributed $81.5 \%$ of measured isoprene, which was often considered as a tracer for biogenic emissions (Situ et al., 2013), so we attributed this factor to biogenic emissions. High loadings of formaldehyde, acetaldehyde, and acetone were also found in this factor. This is possibly because these carbonyls could also be emitted from biogenic sources (Winters et al., 2009), and they were important oxidation products of other biogenic VOCs (Carter and Atkinson, 1996).

Based on the derived profiles of each factor and the distributions of species among these factors, we identified that two of the four PMF-resolved factors could represent primary emission sources, another related to biogenic emissions, and the other was an aged emission factor. As discussed in Sect. 2.2, the relationship between the contribution of one factor to each NMHC species and its chemical reactivity could be used to distinguish factors related to photochemically aged emissions from those for fresh emissions. Such a relationship was shown in Fig. 3, where each NMHC species was shown as a circle. Positive correlations were identified for factors 1 and 2, and thus these two factors were considered to be related to fresh emissions. However, a significant negative correlation was identified for factor 3 , indicating that this factor represented photochemically aged emissions. 

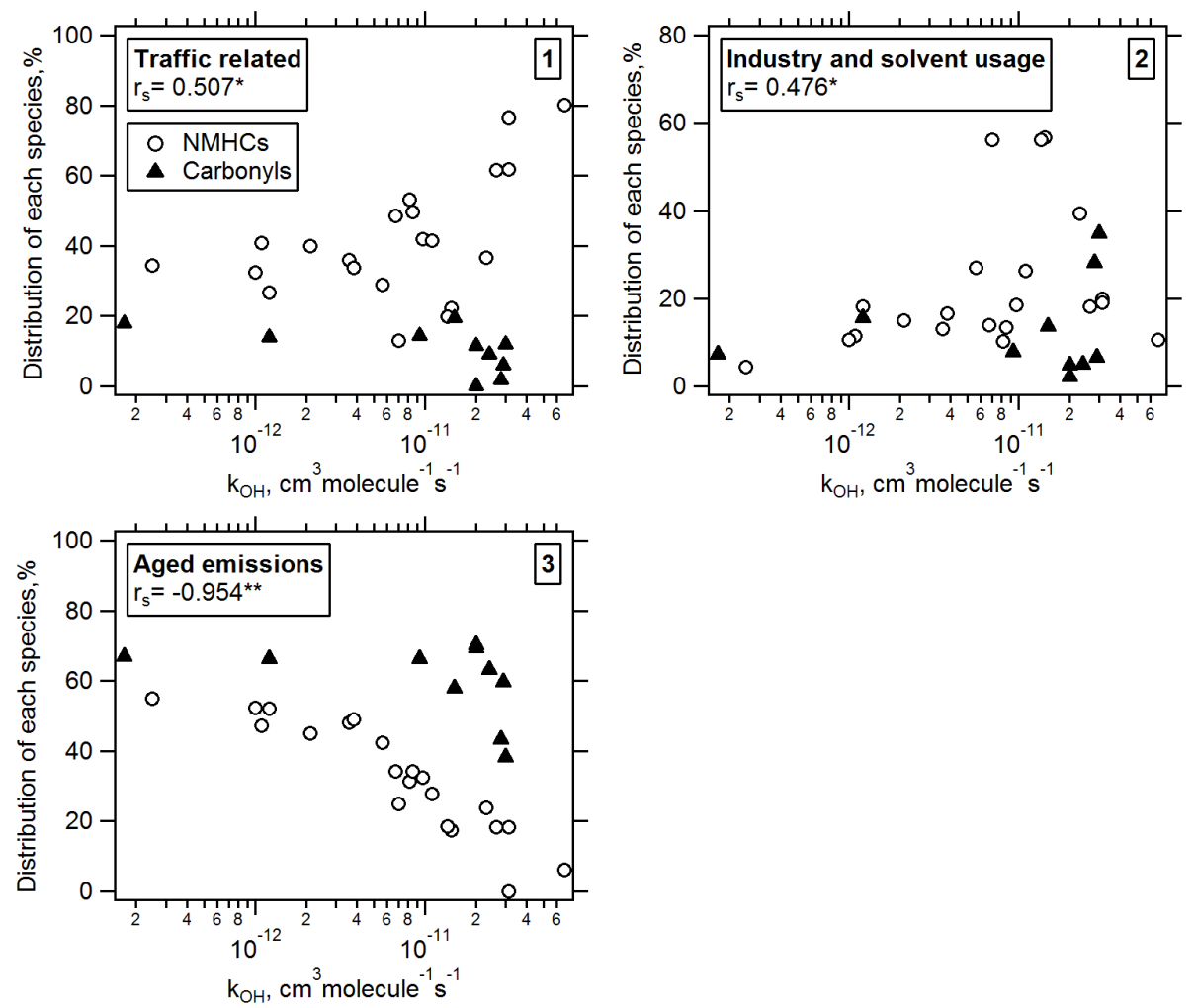

Fig. 3. Relationships between the factor contributions to each NMHC species and $k_{\mathrm{OH}}$ values for NMHC species in summer. Each circle represents one compound. Carbonyls are shown as solid triangles in the graph, but they were not used for correlation analysis due to their secondary production. ${ }^{*}$ indicates a significant correlation at a confidence level of $0.05 .{ }^{* *}$ indicates a significant correlation at a confidence level of 0.01 .

The distributions of carbonyls in PMF-resolved factors were shown in Fig. 3 by solid triangles. If all factors were related to fresh emissions, the distributions of carbonyls would be similar to the distributions of NMHCs in each factor. Due to the influence from photochemical aging, the distribution of carbonyls could be higher in aged factors owing to their secondary production, and meanwhile the distributions of carbonyls would be lower in fresh factors. In factors 1 and 2 , the distributions of carbonyls were similar or lower than those of NMHCs, whereas the distributions of carbonyls in factor 3 were higher than those of NMHCs. Such appearance agreed with our above identifications on PMF-resolved factors.

In this study, two fresh factors and an aged factor were identified in the summer of 2011. However, Yuan et al. (2012) identified one mixed fresh factor and two aged factors with different photochemical ages, using a similar analysis approach based on measurements at the same site in the summer of 2010. It was interesting to get such different results in two consecutive years. Yuan et al. (2012) concluded that PMF results depended on the degree of photochemical processing and the differences in emission compositions of various sources. Assuming that the differences in VOC emissions were not significant between 2010 and 2011, the PMF results were mainly influenced by the difference in degrees in photochemical aging between these two years. We used the ratio of o-xylene to ethylbenzene as an indicator of the degree of photochemical processing. As seen in Fig. S4, the relative standard deviations of o-xylene / ethylbenzene ratios in 2010 were $30 \%$ larger than those in 2011. It indicated that the range of photochemical processing degrees was larger in 2010. As a result, the PMF factors in 2010 were extracted mainly according to different degrees of photochemical processing, whereas the PMF factors in 2011 could be extracted mainly based on individual sources.

In winter, 341 samples were used for the PMF analysis, and five factors were identified (Fig. 4).

Factor 1 and factor 3 contributed to most of our measured alkanes and alkenes, but there were some differences between these two factors. Factor 1 had higher contributions to C2-C3 NMHCs, while factor 3 had higher contributions to C4-C5 NMHCs. These light hydrocarbons were mainly generated by incomplete combustion processes, such as vehicle exhaust and coal burning (Liu et al., 2008; Wang et al., 2013). The measured source profiles in China showed that $\mathrm{C} 2-\mathrm{C} 3$ NMHCs contributed more than half of NMHCs that emitted from coal burning (Liu et al., 2008; Wang et al., 2013). Benzene and toluene also made important contributions to factor 1 . These two species were also found to be important 

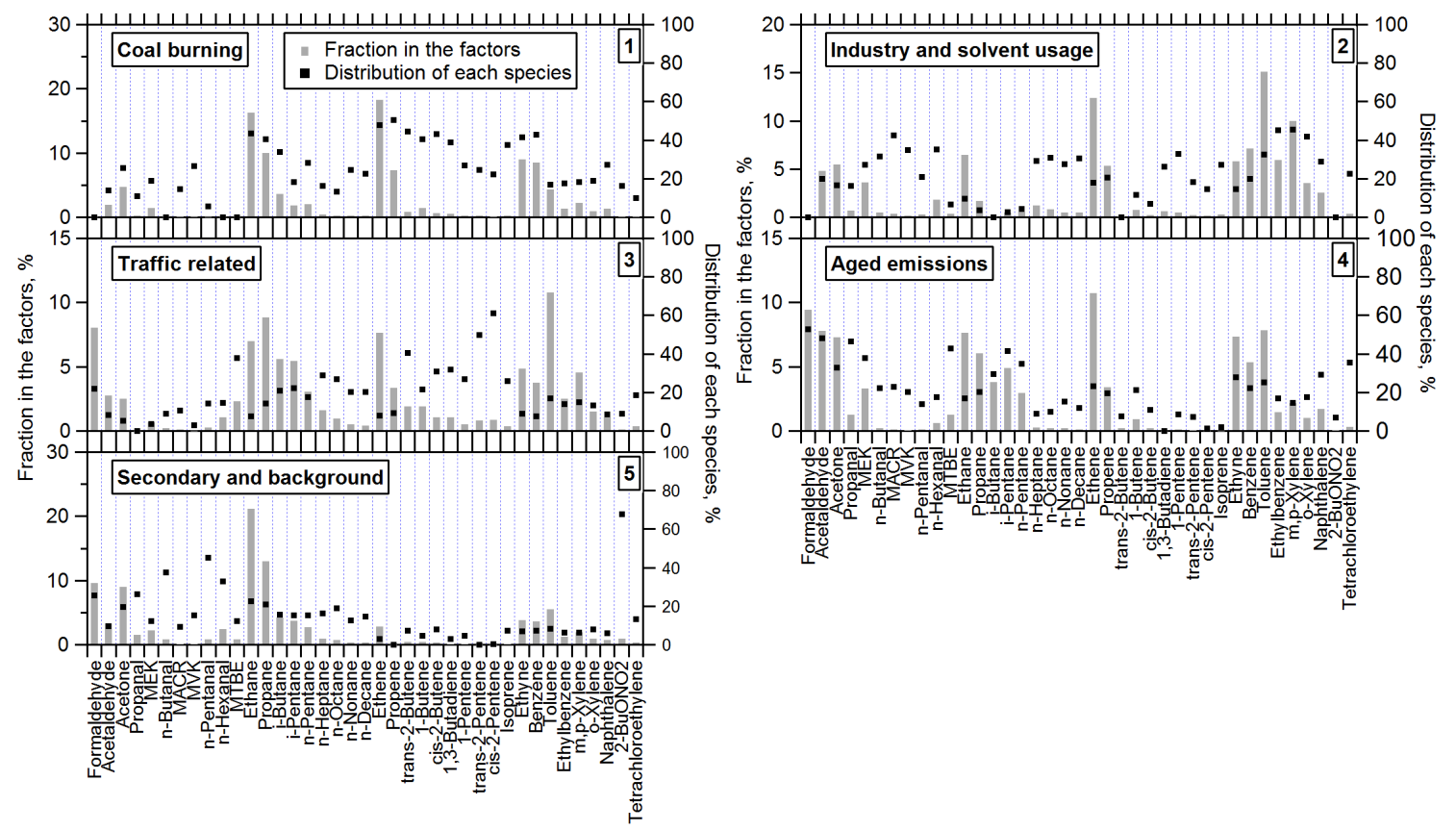

Fig. 4. Profiles of the five factors resolved by the PMF model and the distributions of species among these factors in winter.

components in NMHCs emissions from coal burning (Liu et al., 2008). The ratio of benzene to toluene (2.31 ppb ppb $\left.{ }^{-1}\right)$ in this factor fell between the ratios measured by Liu et al. (2008) for residential coal burning (1.81 $\left.\mathrm{ppb} \mathrm{ppb}^{-1}\right)$ and industrial coal burning $\left(2.62 \mathrm{ppb} \mathrm{ppb}^{-1}\right)$, but much higher than that measured in the tunnel experiment $\left(0.70 \mathrm{ppb} \mathrm{ppb}^{-1}\right)$ (Liu et al., 2008); therefore, factor 1 was identified as coal burning. C4-C5 NMHCs were important species from traffic related emissions, and factor 3 showed similar characteristic with factor 1 in summer. In addition, factor 3 explained $37.9 \%$ of the measured MTBE. Therefore, factor 3 was attributed to traffic related emissions.

Factor 2 had high contributions to aromatics, and showed similar characteristic with the resolved factor 2 for summertime measurements. Besides aromatics, this factor contributed about $30 \%$ of measured long-chain alkanes $(\mathrm{C} 7-$ $\mathrm{C} 10$ alkanes). The long-chain alkanes were also considered to be important components of printing VOC emissions (Yuan et al., 2010). Thus, this factor was identified as industry and solvent usage.

Both factor 4 and factor 5 had important contributions to carbonyls but little contribution to reactive NMHCs, and therefore these two factors were inferred to possibly not represent fresh emissions. The major NMHC species in factor 4 were C2-C5 alkanes, ethene, ethyne, benzene, and toluene. These species could be emitted from all of the three primary factors discussed above, and thus we considered this factor to be aged emissions from these anthropogenic sources. The NMHCs in factor 5 were dominated by unreactive alkanes, such as ethane and propane, so factor 5 was at a more aged stage than factor 4 . Factor 5 accounted for $67.7 \%$ of the measured $2-\mathrm{BuONO}_{2}$ levels and $19.7 \%$ of the measured carbonyl levels. According to the abundances of alkyl nitrates and unreactive alkanes, we considered that the loadings of VOC species in this factor were related to secondary production and background levels.

Similarly with summertime measurements, the relationships between the contribution of one factor to each NMHC species and $k_{\mathrm{OH}}$ values for each NMHC species were analyzed. As shown in Fig. 5, no significant correlation was observed for factor 1 and factor 2, while a positive correlation was found for factor 3 , and thus these three factors were considered to be fresh emissions. Significant negative correlations were identified for factor 4 and factor 5 , indicating that these two factors were influenced by photochemical aging.

\subsection{Exploring the aged and fresh emission factors}

In the last section, we distinguished photochemically aged factors from fresh factors. To better understand the relationships between aged and fresh factors and the role of photochemical aging in PMF analysis, we explored the relationships between VOC consumption and carbonyl formation in the aged factors.

For two factors representing different photochemical stages of the same emissions, the ratios of NMHC abundances in these two factors should follow the equation below (Yuan et al., 2012):

$\frac{[\mathrm{NMHC}]_{\text {aged }}}{[\mathrm{NMHC}]_{\text {fresh }}}=D \times e^{-k_{\mathrm{OH}, \mathrm{NMHC}}[\mathrm{OH}] \Delta t}$ 

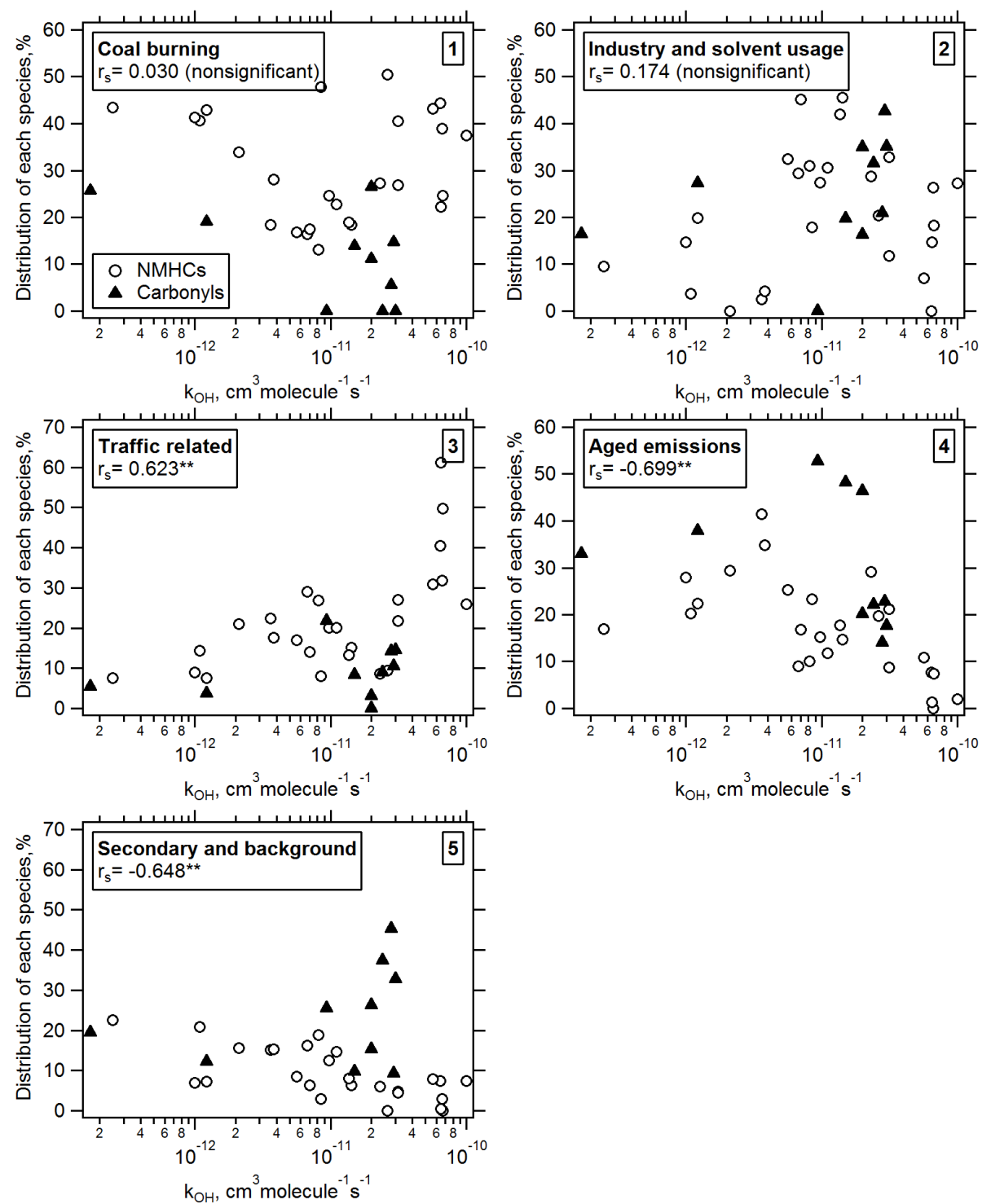

Fig. 5. Relationships between the factor contributions to each NMHC species and $k_{\mathrm{OH}}$ values of NMHC species in winter. Each circle represents one compound. Carbonyls are shown as solid triangles in the graph, but they were not used for correlation analysis due to their secondary production. ${ }^{* *}$ indicates a significant correlation at a confidence level of 0.01 .

where $[\mathrm{NMHC}]_{\mathrm{aged}}$ and $[\mathrm{NMHC}]_{\text {fresh }}$ (ppb) refer to the abundances of NMHC species in the aged and fresh factor, respectively. $D$ is a scaling factor, which normalizes the NMHC abundances to unity. $k_{\mathrm{OH}, \mathrm{NMHC}}$ is the $\mathrm{OH}$ rate constant for the NMHC. $[\mathrm{OH}]$ is the average concentration of $\mathrm{OH}$ radical, and $\Delta t$ is the difference of reaction time between the aged and fresh factors. In this study, the $\mathrm{OH}$ exposure (i.e., the time integrate of $[\mathrm{OH}])$, expressed by $[\mathrm{OH}] \Delta t$, is calculated as a whole.

As discussed in Sect. 3.2, for wintertime measurements, the $[\mathrm{NMHC}]_{\text {aged }}$ refers to the abundances of NMHC in factor 4 , while the $[\mathrm{NMHC}]_{\text {fresh }}$ refers to the sum of the abundances of NMHC in factors 1-3. For summertime measurements, the $[\mathrm{NMHC}]_{\text {aged }}$ refers to the abundances of NMHC in factor 3 , while the $[\mathrm{NMHC}]_{\text {fresh }}$ refers to the sum of the abundances of NMHC in factors 1 and 2. Figure 6 showed the dependence of $[\mathrm{NMHC}]_{\mathrm{aged}} /[\mathrm{NMHC}]_{\text {fresh }}$ (circles in the figure) on $k_{\mathrm{OH}}$ values, with the lines being the fitted results from Eq. (4). The values of $D$ and $[\mathrm{OH}] \Delta t$ were estimated to be 0.43 and $2.99 \times 10^{10}$ molecule $\mathrm{cm}^{-3} \mathrm{~s}$ in winter, and 1.26 and $1.05 \times 10^{11}$ molecule $\mathrm{cm}^{-3} \mathrm{~s}$ in summer, respectively. Referring to the calculated $\mathrm{OH}$ radical concentrations in the summer in Beijing (Z. Liu et al., 2012) and the differences of measured $\mathrm{OH}$ concentrations in Tokyo between summer and winter (Kanaya et al., 2007), we assumed that the average daytime concentration of $\mathrm{OH}$ in Beijing was $1.5 \times 10^{6}$ and $6 \times 10^{6}$ molecule $\mathrm{cm}^{-3}$ in winter and summer; thus, the 

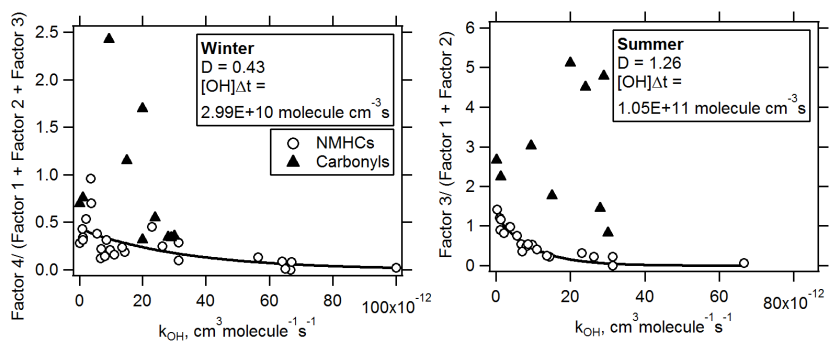

Fig. 6. Relationships between the ratios of VOCs abundances in the aged emissions factors with those in fresh emission factors and $k_{\mathrm{OH}}$ values for each VOC species. Each data point represents one compound. The lines are the fitted results from Eq. (4).

photochemical ages of the aged factor in winter and summer were estimated to be 5.5 and $4.9 \mathrm{~h}$, respectively.

The $[\text { carbonyl }]_{\text {aged }} /[\text { carbonyl }]_{\text {fresh }}$ ratios (Fig. 6, solid triangles) were significantly higher than the ratios of $[\mathrm{NMHC}]_{\text {aged }} /[\mathrm{NMHC}]_{\text {fresh }}$ because secondary production enhanced the abundances of carbonyls in aged factors. As shown in Eq. (5), the abundances of carbonyls in aged factors can be separated into two parts. The first part stands for aged primary emissions and the second part stands for secondary formation calculated based on the consumption of other VOCs:

$[\text { carbonyl }]_{\text {aged }}=D \times[\text { carbonyl }]_{\text {fresh }} \times e^{-k_{\mathrm{OH}, \text { carbonyl }} \times[\mathrm{OH}] \Delta t}$

$+D \times \sum\left([\mathrm{VOC}]_{\mathrm{fresh}} \times\left(1-e^{-k_{\mathrm{OH}, \mathrm{VoC}} \times[\mathrm{OH}] \Delta t}\right) \times Y_{\mathrm{VOC}, \text { carbonyl }},\right)$

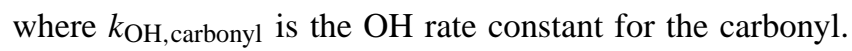
$Y_{\mathrm{VOC}, \text { carbonyl }}(\mathrm{ppb} / \mathrm{ppb})$ refers to the carbonyl production yield from the oxidation of particular VOC, which can be estimated using the Leeds master chemical mechanism (MCM v3.2 http://mcm.leeds.ac.uk/MCM/). The estimation of $Y_{\mathrm{VOC}}$, carbonyl is based on the following assumptions: the removal of $\mathrm{VOC}$ is governed by the reaction with $\mathrm{OH}$ radicals and the removal of alkyl peroxyl radicals $\left(\mathrm{RO}_{2}\right)$ is governed by the reaction with NO. The $Y_{\mathrm{VOC}}$, carbonyl values used in this study are listed in Table 2. The VOC species that make no contributions to the production of our focused carbonyls were not shown in this study. The values of $D$ and $[\mathrm{OH}] \Delta t$ were fitted from Eq. (4).

The carbonyl abundances in aged factors were calculated by Eq. (5) and agreed well with the PMF-resolved abundances (Fig. 7). In winter, all data points were distributed near the $1: 1$ line. In summer, though the data points showed some variability, but still agreed within a factor of two. The agreement between the calculated and PMF-resolved carbonyl abundances indicated that our understanding on the photochemical aging of PMF factors was acceptable. The differences between the calculated and PMF-resolved carbonyl abundances may be due to one or some of the following reasons: (1) the PMF analysis and $Y_{\mathrm{VOC}}$, carbonyl estimations have their own uncertainties. (2) Only reactions of
VOCs with $\mathrm{OH}$ radicals are considered in our analysis. (3) Further reactions of secondary carbonyls are not considered in our analysis. (4) Some VOC species are not applied in our PMF analysis, but they might be precursors of carbonyls. The PMF-analyzed VOC species accounted for $90 \%$ and $87 \%$ of total concentrations of all measured VOCs species in winter and summer, respectively. However, the contribution of each VOC to the formation of carbonyls was not only dependent on its concentration but also its ability to produce carbonyls.

In this work, we identified the PMF factors in summer and winter as several individual fresh emissions and several mixed aged emissions with different degrees of photochemical processing. Beijing was a large city with extensive and continuous local emissions, and therefore our measured air mass was in fact a mixture of fresh and aged plumes. The fresh emissions were separated by the PMF model according to the correlations among VOC species and the different emission characteristics of these sources. However, the resolved factors by the PMF model cannot represent the emissions at different aged stages from individual sources. As discussed in this section, the respective photochemical ages of the aged factors in winter and summer were respectively about 5.5 and $4.9 \mathrm{~h}$, and the factor representing secondary production and background levels in winter should be more aged. We conjectured that VOCs from different sources have been well mixed during such long aging process, and it was hard to identify the aged contributions from individual sources. Likewise, previous studies also used averaged emission ratios to characterize the emission and aging process of urban VOC emissions (de Gouw et al., 2005; Warneke et al., 2007; Yuan et al., 2012; Borbon et al., 2013). In this section, we proved the reasonability of the PMF-derived aged factors. However, one problem remained when apportioning reactive VOCs using the PMF model. Actually, the photochemical reaction of VOCs in the atmosphere is a continuous process, but the PMF model is not able to describe such kind of process. In this work, several different aged stages were recognized by the PMF model and the PMF model used the linear combination of these stages to describe the continuous photochemical process. This might be an important issue for the PMF analysis, and the influence of such approximation required future researches.

\subsection{Primary and secondary sources of carbonyls}

The calculated relative contributions of carbonyl sources apportioned by the PMF model in Beijing were shown in Fig. 8 . Previous studies usually attributed all carbonyls in aged factors as secondary formation. As discussed in Sect. 3.3, the abundances of carbonyls in aged factors could be separated into two parts, that is, the aged direct emissions and the production from VOC consumption, and the former part should be treated as primary emissions. In this study, the aged direct emission part was further separated into each fresh factor considering their relative contributions. For all 
Table 2. Production yields of carbonyls from VOCs (unit: ppb/ppb) http://mcm.leeds.ac.uk/MCM/.

\begin{tabular}{|c|c|c|c|c|c|}
\hline NMHC & Formaldehyde & Acetaldehyde & Acetone & Propanal & Butanal \\
\hline Ethane & 0 & 0.991 & 0 & 0 & 0 \\
\hline Propane & 0 & 0 & 0.705 & 0.259 & 0 \\
\hline i-Butane & 0.773 & 0 & 0.774 & 0 & 0 \\
\hline n-Butane & 0 & 0.581 & 0 & 0 & 0.024 \\
\hline i-Pentane & 0 & 0.606 & 0.611 & 0 & 0 \\
\hline n-Pentane & 0 & 0.114 & 0 & 0.116 & 0 \\
\hline 2,2-dimethylbutane & 0.282 & 0.289 & 0.282 & 0 & 0 \\
\hline 2,3-dimethylbutane & 0 & 0 & 1.638 & 0 & 0 \\
\hline 2-methylpentane & 0 & 0.035 & 0.195 & 0.192 & 0 \\
\hline 3-methylpentane & 0 & 0.491 & 0 & 0 & 0 \\
\hline Ethene & 1.6 & 0 & 0 & 0 & 0 \\
\hline Propene & 0.979 & 0.979 & 0 & 0 & 0 \\
\hline trans-2-Butene & 0 & 1.918 & 0 & 0 & 0 \\
\hline 1-Butene & 0.961 & 0 & 0 & 0.961 & 0 \\
\hline i-Butene & 0.988 & 0 & 0.988 & 0 & 0 \\
\hline cis-2-Butene & 0 & 1.918 & 0 & 0 & 0 \\
\hline 1,3-Butadiene & 0.73 & 0 & 0 & 0 & 0 \\
\hline 1-Pentene & 0.941 & 0 & 0 & 0 & 0.941 \\
\hline cis-2-Pentene & 0 & 0.936 & 0 & 0.936 & 0 \\
\hline trans-2-Pentene & 0 & 0.936 & 0 & 0.936 & 0 \\
\hline Isoprene & 0.709 & 0 & 0 & 0 & 0 \\
\hline Styrene & 1 & 0 & 0 & 0 & 0 \\
\hline Acetaldehyde & 0.999 & 0 & 0 & 0 & 0 \\
\hline Acetone & 1.998 & 0 & 0 & 0 & 0 \\
\hline Propanal & 0 & 0.991 & 0 & 0 & 0 \\
\hline MEK & 1.390 & 0.540 & 0 & 0 & 0 \\
\hline n-Butanal & 0.013 & 0.013 & 0 & 0.832 & 0 \\
\hline MACR & 0.978 & 0 & 0 & 0 & 0 \\
\hline MVK & 0.994 & 0 & 0 & 0 & 0 \\
\hline$n$-Pentanal & 0 & 0 & 0 & 0 & 0.154 \\
\hline
\end{tabular}
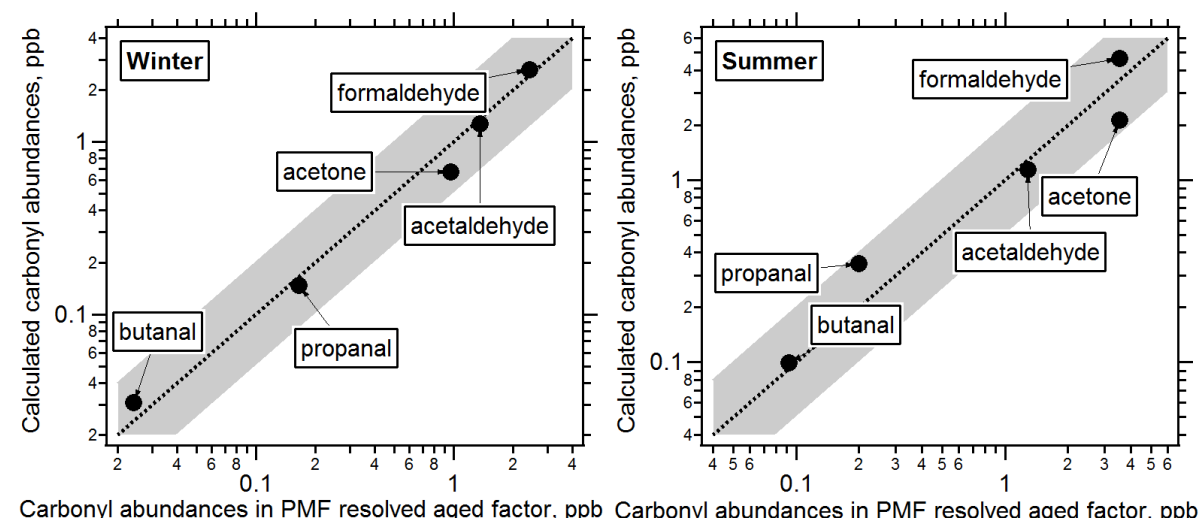

Fig. 7. Comparison of carbonyl abundances calculated based on VOCs consumptions with PMF-resolved abundances in aged factor. The grey shaded area shows an agreement within a factor of two.

the measured carbonyls, secondary formation was the major source in both winter and summer, with relative contributions of $51.2 \%$ and $46.0 \%$, respectively. In winter, the three primary emission sources, that is, coal burning, industry and solvent usage, and traffic related emissions, had similar con- tributions to ambient carbonyl levels (15.3-16.9\%). In summer, $17.0 \%$ and $26.6 \%$ of carbonyls were attributed to industry and solvent usage, and traffic related emissions, respectively. In addition, $10.4 \%$ of carbonyls in summer were considered to be from biogenic emissions or their oxidation. 

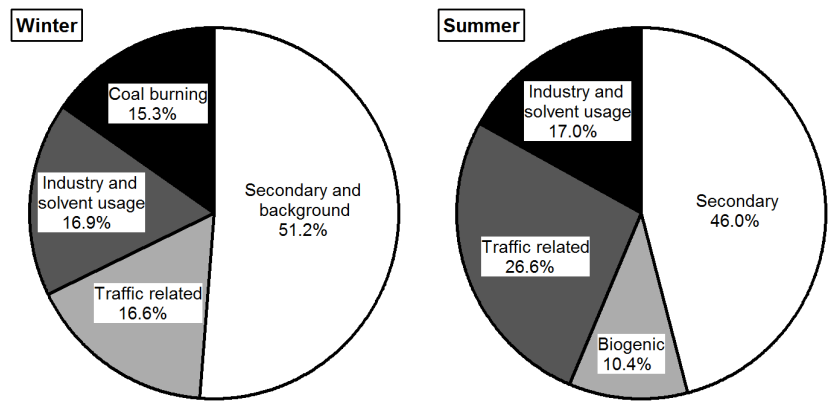

Fig. 8. The relative contributions of carbonyl sources in Beijing derived by the PMF model during winter and summer.

The relative contributions of carbonyls from primary emissions and from secondary formation did not change much between winter and summer, which agreed with the diurnal variation characteristics of carbonyl / NMHC ratios as discussed in Sect. 3.1. However, such results differed from those of Possanzini et al. (2002) and Bakeas et al. (2003) who found great differences between carbonyl sources in winter and summer. Hence, we used the carbonyl production rate $\left(F_{\mathrm{p}}\right)$ to compare carbonyl formation between these two seasons. The $F_{\mathrm{p}}$ can be calculated using Eq. (6) (Lin et al., 2012).

$F_{\mathrm{p}}=\sum\left([\mathrm{VOC}]_{i} \times k_{\mathrm{OH}, \mathrm{VOC}} \times[\mathrm{OH}] \times Y_{\mathrm{VOC}, \text { carbonyl }}\right)$

where $Y_{\mathrm{VOC}, \text { carbonyl }}$ is the carbonyl formation yield of $\mathrm{VOC}$ (Table 2). $[\mathrm{OH}]$ and $[\mathrm{VOC}]_{i}$ are concentrations of $\mathrm{OH}$ radicals and each VOC species, respectively. The values of $[\mathrm{OH}]$ in winter and summer were assumed to be $1.5 \times 10^{6}$ and $6 \times 10^{6}$ molecule $\mathrm{cm}^{-3}$, as discussed in Sect. 3.3. The calculated $F_{\mathrm{p}}$ was 2.3 and $3.6 \mathrm{ppbh}^{-1}$ for formaldehyde, 0.9 and $1.3 \mathrm{ppbh}^{-1}$ for acetaldehyde, 0.3 and $0.4 \mathrm{ppbh}^{-1}$ for acetone in winter and summer, respectively. Though the $\mathrm{OH}$ concentrations in summer were much higher than the values in winter, concentrations of NMHCs, especially alkenes, were much higher in winter. As a result, $F_{\mathrm{p}}$ in summer was only $31-53 \%$ higher than that in winter. For primary emissions, though the levels of NMHCs were higher in winter, the emission ratios of carbonyl to ethyne in summer derived from the PMF analysis were 2-5 times higher than those in winter. Therefore, the contributions from primary emissions appeared to be similar between winter and summer.

Though primary and secondary sources had similar relative contributions to ambient carbonyls in winter and summer, there were obvious differences for primary sources between these two seasons. Coal burning was an important primary source for carbonyls in winter. However, it was not identified in summer. In Beijing, coal was widely used for heating in winter, while it was greatly reduced in summer. The emission strengths of biogenic VOCs favored the higher ambient temperature and light intensity in summer (Guenther et al., 2012), and thus the biogenic-related factor was only identified for summertime measurements.
Formaldehyde is one of the most abundant and important carbonyls in the atmosphere. Table 3 listed the source contributions of formaldehyde obtained in this study and compared with the results from previous studies in Beijing and other regions. The contributions of primary anthropogenic sources to formaldehyde were similar in the two seasons, with the values of $28.9 \%$ in winter and $32.3 \%$ in summer. Biogenic sources contributed $11.8 \%$ of the measured formaldehyde in summer, but their contributions were not identified in winter. The contribution of primary anthropogenic sources to formaldehyde obtained in this study was a bit higher than that reported by Yuan et al. (2012), whereas the contribution of biogenic sources was much lower than that reported by Yuan et al. (2012). Based on our PMF results in summer, the biogenic factor (i.e., factor 4) contributed less than $30 \%$ of the measured MVK and MACR (products of isoprene oxidation), and therefore this factor represented relatively fresh emissions from biogenic sources. However, the contribution calculated by Yuan et al. (2012) was for both primary and secondary biogenic sources, and thus the presented value was much higher. Li et al. (2010) calculated that $76 \%$ of formaldehyde was emitted from primary anthropogenic sources, which was much higher than the values from other studies. There were two possible reasons: (1) only 2-days of data were analyzed in the study by Li et al. (2010) and they might not represent the actual source characteristics of formaldehyde in Beijing; and (2) the concentration of ozone, the secondary marker used in the study, might be influenced by the titration of NO. New York City and Mexico City were two mega cities with large populations and large amounts of vehicles, which were similar to the situation of Beijing. The contribution of primary anthropogenic sources in Beijing was similar to that for New York City (Lin et al., 2012) and a bit lower than that for Mexico City (Garcia et al., 2006).

The contributions of primary anthropogenic sources to the levels of other carbonyls were shown in Table 4. Primary anthropogenic sources had higher contribution in winter, due to less secondary production and lower biogenic emissions. The contributions from anthropogenic emissions were more important for ketones than those for aldehydes, with the values larger than $50 \%$ in both winter and summer. Compared with previous studies in Beijing, the contribution from anthropogenic emissions for acetaldehyde in 2011 was similar to the result of 2010 (Yuan et al., 2012), but much higher than 2005 (Liu et al., 2009). This indicated a possible change in acetaldehyde sources between 2005 and 2011. Though the concentrations of acetaldehyde decreased from $3.6 \mathrm{ppb}$ in 2005 (Shao et al., 2009) to $2.3 \mathrm{ppb}$ in 2011, the contribution of anthropogenic emissions increased from $0.6 \mathrm{ppb}$ to $1.0 \mathrm{ppb}$ from 2005 to 2011 . As the specific sources of primary acetaldehyde were not distinguished in 2005, the reasons for such change were unclear. Further research on temporal trends of acetaldehyde levels and sources were needed in the future. For acetone, propanal, and butanal, 
Table 3. Comparison of source apportionment results of ambient formaldehyde obtained in this study with previous studies.

\begin{tabular}{lrrrcc}
\hline City, season & Primary anthropogenic & Biogenic & Secondary & Background \\
\hline Beijing, winter $^{\mathrm{a}}$ & 28.9 & - & \multicolumn{2}{c}{71.1} & \\
Beijing, summer $^{\mathrm{a}}$ & 32.3 & 11.8 & & 55.9 & \\
Beijing, summer $^{\mathrm{b}}$ & 22 & 36 & 28 & 15 \\
Beijing, summer $^{\mathrm{c}}$ & 76 & - & 18 & 5 \\
New York City, summer $^{\mathrm{d}}$ & 30 & - & & 70 & \\
Mexico City, spring $^{\mathrm{e}}$ & 42 & - & $>38$ & & $<21$ \\
\hline
\end{tabular}

Values are presented as percentages (\%) of formaldehyde concentration.

a This study,

b(Yuan et al., 2012),

$\mathrm{c}^{\mathrm{L}} \mathrm{Li}$ et al., 2010),

d(Lin et al., 2012),

e(Garcia et al., 2006).

Table 4. Percentages of carbonyl concentrations from primary anthropogenic sources in this study and previous studies in Beijing.

\begin{tabular}{lrrrr}
\hline Carbonyl & $\begin{array}{r}2011-2012 \\
\text { Winter }^{\mathrm{a}}\end{array}$ & $\begin{array}{r}2011 \\
\text { Summer }^{\mathrm{a}}\end{array}$ & $\begin{array}{r}2005 \\
\text { Summer }^{\mathrm{b}}\end{array}$ & $\begin{array}{r}2010 \\
\text { Summer }^{\mathrm{c}}\end{array}$ \\
\hline Acetaldehyde & 53.7 & 41.6 & 16 & 46 \\
Acetone & 68.1 & 56.2 & 40 & 38 \\
Propanal & 33.9 & 15.8 & 14 & 3 \\
MEK & 71.0 & 62.2 & 47 & 80 \\
Butanal & 49.0 & 15.5 & 8 & 1 \\
\hline
\end{tabular}

Values are presented as percentages $(\%)$ of carbonyl concentration from primary

anthropogenic sources.

aThis study,

b (Liu et al., 2009),

${ }^{c}$ (Yuan et al., 2012).

our results calculated a bit higher contributions from anthropogenic emissions than that of previous studies.

\section{Summary}

In this study, online VOC measurements were conducted at the urban site of Beijing during winter and summer. The PMF receptor model was used as a technique for source apportionment of VOCs. In winter, five factors were identified, namely coal burning, industry and solvent usage, traffic related emissions, aged emissions, and secondary formation plus background levels. In summer, four factors were identified, which were traffic related emissions, industry and solvent usage, aged emissions, and biogenic emissions.

Relationships between the factor contributions to each NMHC species and $k_{\mathrm{OH}}$ values for each NMHC species were analyzed to distinguish photochemically aged emissions from fresh emissions. In both winter and summer, a factor accounted for aged emissions was identified. The aged factor corresponded to the photochemical stages of mixed fresh emissions, and the relationship between the aged and fresh factors was investigated. The results indicated that the formation of carbonyls in the aged factor could be explained by the consumption of VOCs and their carbonyl production yields. In winter, besides the factor for aged emissions, another factor was attributed to secondary formation and background level. This result demonstrated that the PMF analysis could be influenced by the photochemical processing of fresh emissions. Secondary carbonyls might be resolved to more than one factor according to the different degrees of photochemical processing. When using the PMF model for carbonyl source apportionment, the scientific understanding of each factor should be considered with care.

Both PMF results and diurnal variations of carbonyl/NMHC ratios indicated that relative contributions from primary and secondary sources in Beijing did not change much between winter and summer. Such a result was proved by calculating carbonyl production rates, which showed that carbonyl production rates in summer were only $31-53 \%$ higher than the rates in winter due to higher VOCs concentrations in winter. Secondary formation was the major source of carbonyls in Beijing, with the relative contributions of $51.2 \%$ and $46.0 \%$ in winter and summer, respectively. Traffic related emissions, industry and solvent usage were the main sources of primary anthropogenic carbonyls in Beijing. Coal burning was found to be an important anthropogenic source of carbonyls in winter associated with the heating activities. During summertime, biogenic sources contributed $10.4 \%$ of carbonyl levels. For the three major 
carbonyl species - formaldehyde, acetaldehyde, and acetone - the contribution of primary anthropogenic sources was $28.9 \%$ and $32.3 \%, 53.7 \%$ and $41.6 \%$, and $68.1 \%$ and $56.2 \%$ in winter and summer, respectively. These results, derived from source apportionment, could be used to check the source inventories of carbonyls which were in the process of being updated in follow-up studies.

\section{Supplementary material related to this article is available online at http://www.atmos-chem-phys.net/14/ 3047/2014/acp-14-3047-2014-supplement.pdf.}

Acknowledgements. This study was funded by the Natural Science Foundation for Outstanding Young Scholars (grant no. 41125018).

Edited by: X. Tie

\section{References}

Atkinson, R., Baulch, D. L., Cox, R. A., Crowley, J. N., Hampson, R. F., Hynes, R. G., Jenkin, M. E., Rossi, M. J., Troe, J., and IUPAC Subcommittee: Evaluated kinetic and photochemical data for atmospheric chemistry: Volume II - gas phase reactions of organic species, Atmos. Chem. Phys., 6, 3625-4055, doi:10.5194/acp-6-3625-2006, 2006.

Bakeas, E. B., Argyris, D. I., and Siskos, P. A.: Carbonyl compounds in the urban environment of Athens, Greece, Chemosphere, 52, 805-813, doi:10.1016/s0045-6535(03)002571, 2003.

Ban-Weiss, G. A., McLaughlin, J. P., Harley, R. A., Kean, A. J., Grosjean, E., and Grosjean, D.: Carbonyl and nitrogen dioxide emissions from gasoline- and diesel-powered motor vehicles, Environ. Sci. Technol., 42, 3944-3950, doi:10.1021/es8002487, 2008.

Bon, D. M., Ulbrich, I. M., de Gouw, J. A., Warneke, C., Kuster, W. C., Alexander, M. L., Baker, A., Beyersdorf, A. J., Blake, D., Fall, R., Jimenez, J. L., Herndon, S. C., Huey, L. G., Knighton, W. B., Ortega, J., Springston, S., and Vargas, O.: Measurements of volatile organic compounds at a suburban ground site (T1) in Mexico City during the MILAGRO 2006 campaign: measurement comparison, emission ratios, and source attribution, Atmos. Chem. Phys., 11, 2399-2421, doi:10.5194/acp-11-23992011, 2011.

Borbon, A., Gilman, J. B., Kuster, W. C., Grand, N., Chevaillier, S., Colomb, A., Dolgorouky, C., Gros, V., Lopez, M., Sarda-Esteve, R., Holloway, J., Stutz, J., Petetin, H., McKeen, S., Beekmann, M., Warneke, C., Parrish, D. D., and de Gouw, J. A.: Emission ratios of anthropogenic volatile organic compounds in northern mid-latitude megacities: Observations versus emission inventories in Los Angeles and Paris, J. Geophys. Res.-Atmos., 118, 2041-2057, doi:10.1002/jgrd.50059, 2013.

Buzcu Guven, B. and Olaguer, E. P.: Ambient formaldehyde source attribution in Houston during TexAQS II and TRAMP, Atmos. Environ., 45, 4272-4280, doi:10.1016/j.atmosenv.2011.04.079, 2011.
Carter, W. P. L. and Atkinson, R.: Development and evaluation of a detailed mechanism for the atmospheric reactions of isoprene and $\mathrm{NO}_{\mathrm{x}}$, Int. J. Chem. Kinet., 28, 497-530, doi:10.1002/(sici)1097-4601(1996)28:7<497::aidkin4>3.0.co;2-q, 1996.

Cerón, R. M., Cerón, J. G., and Muriel, M.: Diurnal and seasonal trends in carbonyl levels in a semi-urban coastal site in the Gulf of Campeche, Mexico, Atmos. Environ., 41, 63-71, doi:10.1016/j.atmosenv.2006.08.008, 2007.

Chang, C. C., Wang, J. L., Liu, S. C., and Lung, S. C. C.: Assessment of vehicular and non-vehicular contributions to hydrocarbons using exclusive vehicular indicators, Atmos. Environ., 40, 6349-6361, doi:10.1016/j.atmosenv.2006.05.043, 2006.

de Gouw, J. A., Middlebrook, A. M., Warneke, C., Goldan, P. D., Kuster, W. C., Roberts, J. M., Fehsenfeld, F. C., Worsnop, D. R., Canagaratna, M. R., Pszenny, A. A. P., Keene, W. C., Marchewka, M., Bertman, S. B., and Bates, T. S.: Budget of organic carbon in a polluted atmosphere: Results from the New England Air Quality Study in 2002, J. Geophys. Res.-Atmos., 110, D16305, doi:10.1029/2004jd005623, 2005.

De Smedt, I., Stavrakou, T., Müller, J. F., van der A, R. J., and Van Roozendael, M.: Trend detection in satellite observations of formaldehyde tropospheric columns, Geophys. Res. Lett., 37, L18808, doi:10.1029/2010g1044245, 2010.

Finlayson-Pitts, B. J. and Pitts, J. N.: Tropospheric air pollution: Ozone, airborne toxics, polycyclic aromatic hydrocarbons, and particles, Science, 276, 1045-1052, doi:10.1126/science.276.5315.1045, 1997.

Friedfeld, S., Fraser, M., Ensor, K., Tribble, S., Rehle, D., Leleux, D., and Tittel, F.: Statistical analysis of primary and secondary atmospheric formaldehyde, Atmos. Environ., 36, 4767-4775, doi:10.1016/s1352-2310(02)00558-7, 2002.

Garcia, A. R., Volkamer, R., Molina, L. T., Molina, M. J., Samuelson, J., Mellqvist, J., Galle, B., Herndon, S. C., and Kolb, C. E. Separation of emitted and photochemical formaldehyde in Mexico City using a statistical analysis and a new pair of gas-phase tracers, Atmos. Chem. Phys., 6, 4545-4557, doi:10.5194/acp-64545-2006, 2006.

Goldstein, A. H. and Schade, G. W.: Quantifying biogenic and anthropogenic contributions to acetone mixing ratios in a rural environment, Atmos. Environ., 34, 4997-5006, doi:10.1016/s13522310(00)00321-6, 2000.

Guenther, A. B., Jiang, X., Heald, C. L., Sakulyanontvittaya, T., Duhl, T., Emmons, L. K., and Wang, X.: The Model of Emissions of Gases and Aerosols from Nature version 2.1 (MEGAN2.1): an extended and updated framework for modeling biogenic emissions, Geosci. Model Dev., 5, 1471-1492, doi:10.5194/gmd-51471-2012, 2012.

Guo, H., Ling, Z. H., Cheung, K., Wang, D. W., Simpson, I. J., and Blake, D. R.: Acetone in the atmosphere of Hong Kong: Abundance, sources and photochemical precursors, Atmos. Environ., 65, 80-88, doi:10.1016/j.atmosenv.2012.10.027, 2013.

Kanaya, Y., Cao, R., Akimoto, H., Fukuda, M., Komazaki, Y., Yokouchi, Y., Koike, M., Tanimoto, H., Takegawa, N., and Kondo, Y.: Urban photochemistry in central Tokyo: 1. Observed and modeled $\mathrm{OH}$ and $\mathrm{HO}_{2}$ radical concentrations during the winter and summer of 2004, J. Geophys. Res.-Atmos., 112, D21312, doi:10.1029/2007jd008670, 2007. 
Kim, K.-H., Hong, Y.-J., Pal, R., Jeon, E.-C., Koo, Y.-S., and Sunwoo, Y.: Investigation of carbonyl compounds in air from various industrial emission sources, Chemosphere, 70, 807-820, doi:10.1016/j.chemosphere.2007.07.025, 2008.

Lary, D. J. and Shallcross, D. E.: Central role of carbonyl compounds in atmospheric chemistry, J. Geophys. Res.-Atmos., 105, 19771-19778, doi:10.1029/1999jd901184, 2000.

Li, Y., Shao, M., Lu, S., Chang, C.-C., and Dasgupta, P. K.: Variations and sources of ambient formaldehyde for the 2008 Beijing Olympic games, Atmos. Environ., 44, 2632-2639, doi:10.1016/j.atmosenv.2010.03.045, 2010.

Liggio, J., Li, S. M., and McLaren, R.: Reactive uptake of glyoxal by particulate matter, J. Geophys. Res.-Atmos., 110, D10304, doi:10.1029/2004jd005113, 2005.

Lin, Y. C., Schwab, J. J., Demerjian, K. L., Bae, M.-S., Chen, W.N., Sun, Y., Zhang, Q., Hung, H.-M., and Perry, J.: Summertime formaldehyde observations in New York City: Ambient levels, sources and its contribution to HOx radicals, J. Geophys. Res.Atmos., 117, D08305, doi:10.1029/2011jd016504, 2012.

Liu, H., Wang, X. M., Pang, J. M., and He, K. B.: Feasibility and difficulties of China's new air quality standard compliance: PRD case of $\mathrm{PM}_{2.5}$ and ozone from 2010 to 2025, Atmos. Chem. Phys., 13, 12013-12027, doi:10.5194/acp-13-12013-2013, 2013.

Liu, Y., Shao, M., Fu, L., Lu, S., Zeng, L., and Tang, D.: Source profiles of volatile organic compounds (VOCs) measured in China: Part I, Atmos. Environ., 42, 6247-6260, doi:10.1016/j.atmosenv.2008.01.070, 2008.

Liu, Y., Shao, M., Kuster, W. C., Goldan, P. D., Li, X. H., Lu, S. H., and De Gouw, J. A.: Source identification of reactive hydrocarbons and oxygenated VOCs in the summertime in Beijing, Environ. Sci. Technol., 43, 75-81, doi:10.1021/es801716n, 2009.

Liu, Z., Wang, Y., Gu, D., Zhao, C., Huey, L. G., Stickel, R., Liao, J., Shao, M., Zhu, T., Zeng, L., Amoroso, A., Costabile, F., Chang, C.-C., and Liu, S.-C.: Summertime photochemistry during CAREBeijing-2007: $\mathrm{RO}_{\mathrm{x}}$ budgets and $\mathrm{O}_{3}$ formation, Atmos. Chem. Phys., 12, 7737-7752, doi:10.5194/acp-12-77372012, 2012.

Liu, W.-T., Hsieh, H.-C., Chen, S.-P., Chang, J. S., Lin, N.H., Chang, C.-C., and Wang, J.-L.: Diagnosis of air quality through observation and modeling of volatile organic compounds (VOCs) as pollution tracers, Atmos. Environ., 55, 56-63, doi:10.1016/j.atmosenv.2012.03.017, 2012.

Paatero, P. and Tapper, U.: Positive matrix factorization a nonnegative factor model with optimal utilization of error-estimates of data values, Environmetrics, 5, 111-126, doi:10.1002/env.3170050203, 1994.

Pang, X. and Mu, Y.: Seasonal and diurnal variations of carbonyl compounds in Beijing ambient air, Atmos. Environ., 40, 63136320, doi:10.1016/j.atmosenv.2006.05.044, 2006.

Parrish, D. D., Ryerson, T. B., Mellqvist, J., Johansson, J., Fried, A., Richter, D., Walega, J. G., Washenfelder, R. A., de Gouw, J. A., Peischl, J., Aikin, K. C., McKeen, S. A., Frost, G. J., Fehsenfeld, F. C., and Herndon, S. C.: Primary and secondary sources of formaldehyde in urban atmospheres: Houston Texas region, Atmos. Chem. Phys., 12, 3273-3288, doi:10.5194/acp-12-32732012, 2012.

Possanzini, M., Palo, V. D., and Cecinato, A.: Sources and photodecomposition of formaldehyde and acetaldehyde in Rome am- bient air, Atmos. Environ., 36, 3195-3201, doi:10.1016/s13522310(02)00192-9, 2002.

Rappenglück, B., Dasgupta, P. K., Leuchner, M., Li, Q., and Luke, W.: Formaldehyde and its relation to $\mathrm{CO}, \mathrm{PAN}$, and $\mathrm{SO}_{2}$ in the Houston-Galveston airshed, Atmos. Chem. Phys., 10, 24132424, doi:10.5194/acp-10-2413-2010, 2010.

Shao, M., Tang, X., Zhang, Y., and Li, W.: City clusters in China: air and surface water pollution, Front. Ecol. Environ., 4, 353-361, doi:10.1890/1540-9295(2006)004[0353:CCICAA]2.0.CO;2, 2006.

Shao, M., Lu, S., Liu, Y., Xie, X., Chang, C., Huang, S., and Chen, Z.: Volatile organic compounds measured in summer in Beijing and their role in groundlevel ozone formation, J. Geophys. Res.Atmos., 114, D00G06, doi:10.1029/2008jd010863, 2009.

Simpson, I. J., Blake, N. J., Blake, D. R., Atlas, E., Flocke, F., Crawford, J. H., Fuelberg, H. E., Kiley, C. M., Meinardi, S., and Rowland, F. S.: Photochemical production and evolution of selected C2-C5 alkyl nitrates in tropospheric air influenced by Asian outflow, J. Geophys. Res.-Atmos., 108, 8808, doi:10.1029/2002jd002830, 2003.

Singh, H. B., Kanakidou, M., Crutzen, P. J., and Jacob, D. J.: High concentrations and photochemical fate of oxygenated hydrocarbons in the global troposphere, Nature, 378, 50-54, 1995.

Situ, S., Guenther, A., Wang, X., Jiang, X., Turnipseed, A., Wu, Z., Bai, J., and Wang, X.: Impacts of seasonal and regional variability in biogenic VOC emissions on surface ozone in the Pearl River delta region, China, Atmos. Chem. Phys., 13, 1180311817, doi:10.5194/acp-13-11803-2013, 2013.

Song, Y., Dai, W., Shao, M., Liu, Y., Lu, S. H., Kuster, W., and Goldan, P.: Comparison of receptor models for source apportionment of volatile organic compounds in Beijing, China, Environ. Pollut., 156, 174-183, doi:10.1016/j.envpol.2007.12.014, 2008.

Vlasenko, A., Macdonald, A .M., Sjostedt, S. J., and Abbatt, J. P. D.: Formaldehyde measurements by Proton transfer reaction - Mass Spectrometry (PTR-MS): correction for humidity effects, Atmos. Meas. Tech., 3, 1055-1062, doi:10.5194/amt-3-1055-2010, 2010.

Wang, B., Shao, M., Lu, S. H., Yuan, B., Zhao, Y., Wang, M., Zhang, S. Q., and Wu, D.: Variation of ambient non-methane hydrocarbons in Beijing city in summer 2008, Atmos. Chem. Phys., 10, 5911-5923, doi:10.5194/acp-10-5911-2010, 2010.

Wang, M., Shao, M., Chen, W., Yuan, B., Lu, S., Zhang, Q., Zeng, L., and Wang, Q.: Validation of emission inventories by measurements of ambient volatile organic compounds in Beijing, China, Atmos. Chem. Phys. Discuss., 13, 26933-26979, doi:10.5194/acpd-13-26933-2013, 2013.

Wang, Q., Geng, C., Lu, S., Chen, W., and Shao, M.: Emission factors of gaseous carbonaceous species from residential combustion of coal and crop residue briquettes, Front. Environ. Sci. Eng., 7, 66-76, doi:10.1007/s11783-012-0428-5, 2013.

Wang, Y., Konopka, P., Liu, Y., Chen, H., Müller, R., Plöger, F., Riese, M., Cai, Z., and Lü, D.: Tropospheric ozone trend over Beijing from 2002-2010: ozonesonde measurements and modeling analysis, Atmos. Chem. Phys., 12, 8389-8399, doi:10.5194/acp-12-8389-2012, 2012a.

Wang, Y. S., Ren, X. Y., Ji, D. S., Zhang, J. Q., Sun, J., and Wu, F. K.: Characterization of volatile organic compounds in the urban area of Beijing from 2000 to 2007, J. Environ. Sci.-China, 24, 95-101, doi:10.1016/s1001-0742(11)60732-8, 2012b. 
Warneke, C., McKeen, S. A., de Gouw, J. A., Goldan, P. D., Kuster, W. C., Holloway, J. S., Williams, E. J., Lerner, B. M., Parrish, D. D., Trainer, M., Fehsenfeld, F. C., Kato, S., Atlas, E. L., Baker, A., and Blake, D. R.: Determination of urban volatile organic compound emission ratios and comparison with an emissions database, J. Geophys. Res.-Atmos., 112, D10S47, doi:10.1029/2006jd007930, 2007.

Warneke, C., Veres, P., Holloway, J. S., Stutz, J., Tsai, C., Alvarez, S., Rappenglueck, B., Fehsenfeld, F. C., Graus, M., Gilman, J. B., and de Gouw, J. A.: Airborne formaldehyde measurements using PTR-MS: calibration, humidity dependence, intercomparison and initial results, Atmos. Meas. Tech., 4, 23452358, doi:10.5194/amt-4-2345-2011, 2011.

Winters, A. J., Adams, M. A., Bleby, T. M., Rennenberg, H., Steigner, D., Steinbrecher, R., and Kreuzwieser, J.: Emissions of isoprene, monoterpene and short-chained carbonyl compounds from Eucalyptus spp. in southern Australia, Atmos. Environ., 43, 3035-3043, doi:10.1016/j.atmosenv.2009.03.026, 2009.

$\mathrm{Xu}$, Z., Liu, J., Zhang, Y., Liang, P., and Mu, Y.: Ambient levels of atmospheric carbonyls in Beijing during the 2008 Olympic Games, J. Environ. Sci.-China, 22, 1348-1356, doi:10.1016/s1001-0742(09)60261-8, 2010.

Yuan, B., Shao, M., Lu, S., and Wang, B.: Source profiles of volatile organic compounds associated with solvent use in Beijing, China, Atmos. Environ., 44, 1919-1926, doi:10.1016/j.atmosenv.2010.02.014, 2010.
Yuan, B., Shao, M., de Gouw, J., Parrish, D. D., Lu, S., Wang, M., Zeng, L., Zhang, Q., Song, Y., Zhang, J., and Hu, M.: Volatile organic compounds (VOCs) in urban air: How chemistry affects the interpretation of positive matrix factorization (PMF) analysis, J. Geophys. Res.-Atmos., 117, D24302, doi:10.1029/2012jd018236, 2012.

Yuan, B., Hu, W. W., Shao, M., Wang, M., Chen, W. T., Lu, S. H., Zeng, L. M., and Hu, M.: VOC emissions, evolutions and contributions to SOA formation at a receptor site in eastern China, Atmos. Chem. Phys., 13, 8815-8832, doi:10.5194/acp-13-88152013, 2013.

Zhang, J. and Smith, K. R.: Emissions of carbonyl compounds from various cookstoves in China, Environ. Sci. Technol., 33, 23112320, doi:10.1021/es9812406, 1999.

Zhang, Y. J., Mu, Y. J., Liu, J. F., and Mellouki, A.: Levels, sources and health risks of carbonyls and BTEX in the ambient air of Beijing, China, J. Environ. Sci.-China, 24, 124-130, doi:10.1016/s1001-0742(11)60735-3, 2012.

Zheng, J., Garzón, J. P., Huertas, M. E., Zhang, R., Levy, M., Ma, Y., Huertas, J. I., Jardón, R. T., Ruíz, L. G., Tan, H., and Molina, L. T.: Volatile organic compounds in Tijuana during the Cal-Mex 2010 campaign: Measurements and source apportionment, Atmos. Environ., 70, 521-531, doi:10.1016/j.atmosenv.2012.11.030, 2013. 